\title{
PRELIMINARY STUDY OF ON CLADDING PROCESS ON GRAY CAST IRON SUBSTRATE
}

\author{
Hussein, N. I. S ${ }^{1}$, Kamarul S. R. ${ }^{2}$, Ayof, M. $\mathbf{N}^{3}$ \\ ${ }^{1,3}$ Senior Lecturer, Department of Manufacturing Process, Faculty of Manufacturing Engineering, Universiti Teknikal \\ Malaysia Melaka, Malacca, Malaysia, \\ ${ }^{2}$ Student, Department of Manufacturing Process, Faculty of Manufacturing Engineering, Universiti Teknikal Malaysia \\ Melaka, Malacca, Malaysia, \\ izan@utem.edu.my, kamarul.shaufi@student.utem.edu.my,nizam@utem.edu.my
}

\begin{abstract}
Cladding, also called as hardfacing or surfacing, is a deposition process with a purpose of improving the properties of the substrate accomplished either using laser beam or arc as the heat source for the process. Filler material used in the process is deposited layerby-layer until covering required thickness before being machined to achieve the final dimension. Gas metal arc welding is seen as the best method for accomplishing the cladding operation as the alternative for laser cladding in term of operation cost. The process parameters of gas metal arc welding are discussed on in the aspect of the cladding process. Grey cast iron with its inherent brittleness characteristic is difficult to be weld cladded because the thermal cycle of the cladding process can cause the material to crack. It is understood that the coarse graphite flake structure that gives the lack of ductility characteristic to the material and cause the material to crack when suffer the stress occur during the temperature drop of the process. Nickel based filler material is seen as the best choice to be used for the deposition process because of its ability to precipitate carbon in its free form of graphite and prevent the migration of carbon from cast iron substrate thus avoiding the formation of hard carbide phase. The addition of tungsten carbide in the matrix of nickel base alloy gives the filler material good hardness and wear resistant properties. This paper serves as the preliminary study to get an insight into the understanding of cladding process on cast iron as the substrate before performing the experiment of the cladding operation.
\end{abstract}

Keywords: Cladding, Hardfacing, Cast Iron, Nickel Based Alloy

\section{INTRODUCTION}

Surface treatment technology is employed to functional parts with the purpose to ensure that they possess certain properties and characteristics like wear and corrosion resistant and high hardness. Some example of surface treatment processes are mechanical plating, case hardening, thermal spraying, vapor deposition, and cladding technique. The weld cladding technique, either for the purpose of manufacturing or repairing components, is commonly used in wide range of industries [1]. In manufacturing industry, the term cladding may refer to roll cladding, explosive cladding, sheet cladding, or braze cladding [2], but throughout this paper the term cladding is strictly focused to weld cladding.

\subsection{Cladding}

Cladding, also called as Hardfacing or surfacing, is a type of deposition process where a filler material is deposited onto the substrate layer-by-layer with the objective to improve the properties of the substrate. The cladding process can be accomplished by using either laser beam or arc as the heat source for melting the filler material during depositing onto the surface of the substrate. Laser cladding technique is the cladding process that utilizes laser beam as the heat source and the filler material is deposited by powder injection [3].

Weld cladding technique is the cladding process that utilizes arc as the heat source which is accomplished using welding equipment. Weld cladding process is similar to arc welding process but the difference is that weld cladding not aiming for joining separate parts. Weld cladding can be realized through any one of these arc welding techniques; gas metal arc welding (GMAW), flux cored arc welding (FCAW), shielded metal arc welding (SMAW), gas tungsten arc welding (GTAW), plasma arc welding (PAW), and electroslag welding (ESW) [2].

\subsection{Background of Development}

Weld cladding techniques were initially developed for the use of navy defense components by Strachan \& Henshaw, Bristol; a major defence and nuclear engineering company [2]. The developed cladding techniques were to be used on components 
where the equipment needs to work in seawater with minimum maintenance and be exposed to very high pressure and shock loading. The revolution of cladding process is comparable to rapid prototyping and rapid manufacturing using layered processes [4]. Nowadays, the cladding techniques are being utilized in a wide range of industries such as food processing, fertilizer, chemical, petrochemical, automotive, and, nuclear and power plant $[1,2,5,6]$.

\subsection{Principle of the Process}

In cladding techniques, the filler material is deposited onto the substrate in multiple of layers until essential thickness is achieved before being machined to achieve the required dimension. Figure 1 shows an arrangement of bead and interpasses of weld clad onto cast iron substrate based on the work of Buchanan et al. [1] in their study on microstructure and wear resistant behaviour cladding on grey cast iron. The filler material is deposited until three layers and then, the clad machined to get the total thickness of $6 \mathrm{~mm}$.

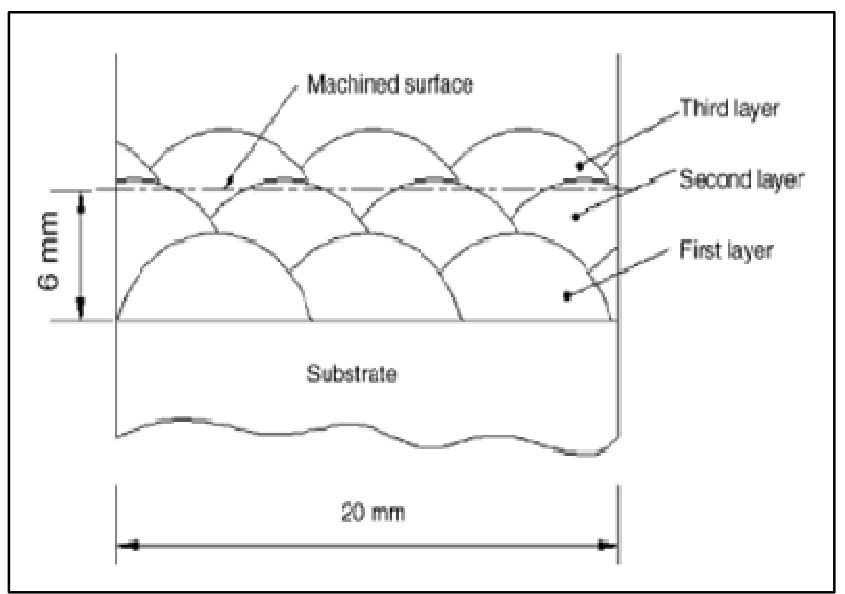

Fig-1: Arrangement of bead and interpasses of weld onto cast iron substrate [1].

There is also another situation where the clad is deposited just to cover a small portion of a surface like in repair welding. In the case where crack happened on cast steels, a certain amount of material from the cast steels is removed in shape of $\mathrm{V}$ groove around the crack before the weld-repair is performed [5]. Figure 2 shows the cladding layers arrangement of the repair welding using the principle of buttering technique based on the work of Branza et al. [5] in their study on weld-repair on heat-resistant cast steels.

Figure 2 is showing the principle of buttering technique which passes 1-12 are buttering passes with a soft and ductile filler material and passes 13-26 are filling passes with a heatresistant filler metal. The idea of using soft ductile filler material for the buttering passes is to sustain strain and stress which generated by the welding process and therefore prevent crack from occurring.

\subsection{Application in Industries}

The weld cladding technique is regularly applied in various types of industries, either for the purpose of maintenance or manufacturing new component [1]. According to Buchanan et al. [1], the cladding technique is used to reduce wear of grey cast iron mill rollers in the sugarcane industry. Reducing the wear of the rollers helps in the use of greater extraction loads and better movement of the crushed cane through the rollers.

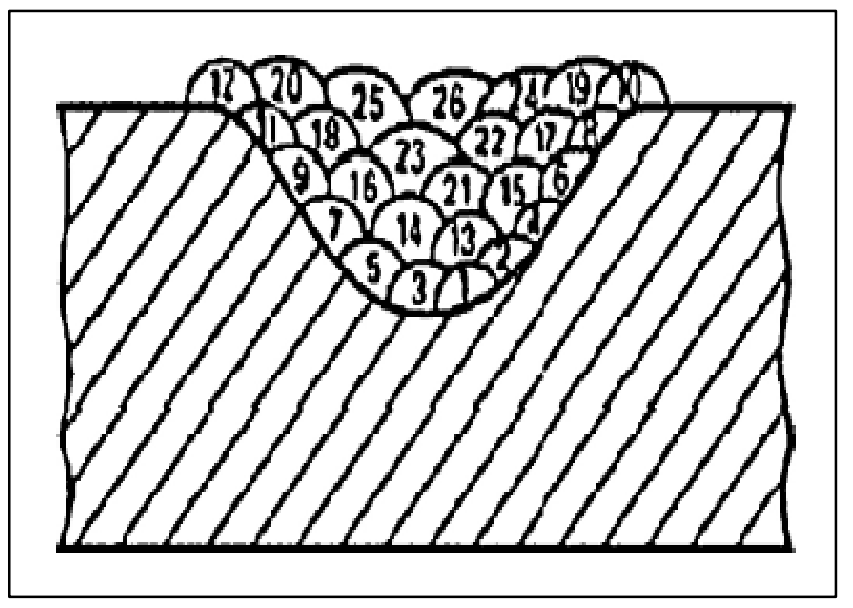

Fig-2: Cladding layers arrangement of weld-repair on heatresistant cast steels [5].

Cladding is also used for repair welding on heat-resistant cast steels which are widely used for the manufacturing of component parts for the petrochemical industry [5]. Whereas Chatterjee and Pal [6], stated that cladding is used on top bearing plate of coal crushing unit in power plant industry in India.

\section{GAS METAL ARC WELDING (GMAW)}

Gas metal arc welding is one of the arc welding techniques widely utilized for the cladding process. GMAW offers a relative economical and low cost but high power density and allows good process control rate of rapid processing [7]. By providing proper manipulation system, GMAW has high potential in being operated for robust and rapid layered deposition processes.

\subsection{GMAW Based Deposition Process}

GMAW technique uses consumable electrode which is in the form of wire feedstock and according to Clark et al. [7], the use of consumable electrode offers a standard consumable form provides consistent feed angles during the additive manufacturing process which is a significant advantage. Also, 
the deposition process using wire feedstock, if compared to the powder-based techniques, has further advantage in the aspect of material utilization.

Schneebeli et al. [8] was the first to propose wire-based metal deposition. In gas metal arc (GMA) shape metal deposition system, the consumable electrode wire is melted by the generated arc and the droplets of molten metal are deposited onto a substrate in a sequential of layers until specific width are covered. This shaped metal deposition process has potential application in building a structure (rapid manufacturing) and repairing worn out parts. Zhang et al. [9] has established GMAW-based rapid prototyping system performing layered deposition process and able to fabricating numerous complex parts. However, the case of rapid prototyping is difference from weld cladding as its purpose is not for improving the properties of the substrate.

\subsection{Process Parameters in GMAW}

In weld cladding through the method of GMAW, the role process parameters is a bit difference from the welding for joining purpose as in cladding, the depth of penetration of the process need to be as minimum as possible to get minimum dilution [12]. The required optimum parameters to be achieved are not for the quality of joining parts but for the quality of the clad.

Karadeniz et al. [10] mentioned that the parameters of GMAW can be divided into several groups. The first group is the first order adjustable parameters which are the welding current, arc voltage and welding speed. The second group is the second order adjustable parameters consist of the torch angle, free wire length, nozzle distance, welding direction, welding position, and the flow rate of shielding gas. These two groups are the parameters defined before the welding process and can be changed during the process. Furthermore, the wire electrode diameter and its chemical composition, and the type of shielding gas are the parameters defined before starting the welding process and cannot be changed during the welding process.

The arc and the welding bath are affected by the process parameters and when all the parameters are in conformity, the perfect arc can be achieved [10, 11]. Karadeniz et al. [10] also stated that enough penetration, high heating rate and right welding profile are the aspects of welding joint quality. However, in this paper, the discussion of using GMAW is for cladding purpose and not for joining two separated parts. There are differences in terms of quality between the bead of weld-cladding and weld-joining.

When cladding is performed, the preferred geometry of the bead is the one which has minimum penetration depth, maximum bead width, reinforcement, and minimum dilution percentage [12]. Figure 3 shows the weld bead geometry as defined by Palani et al. [12].

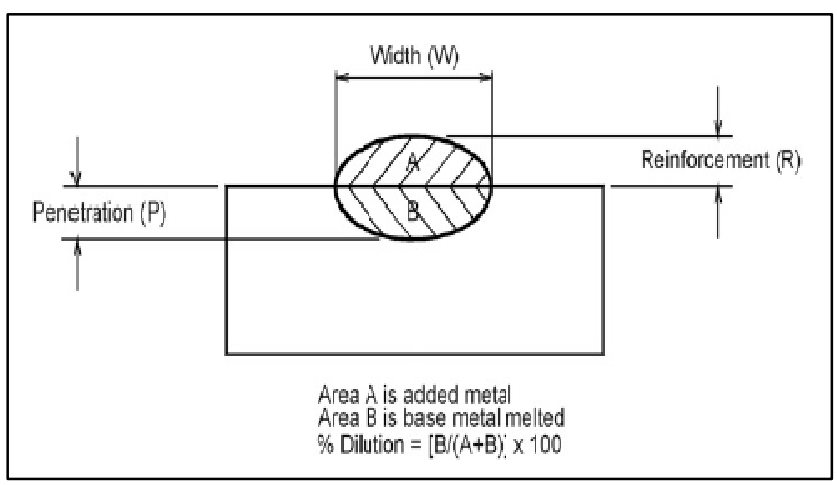

Fig-3: Weld bead geometry [12].

\subsection{Current}

Increase in welding current leads to increasing depth of penetration and bead width [13]. In their research on the effect of process parameters on penetration in GMAW using DIN EN 10120 steel as the substrate, Karadeniz et al. [10] found that the welding current affects penetration depth about 2.5 times greater than arc voltage and travel speed. Getting the optimum value of welding current is important because as far as cladding is concerned, minimum depth of penetration needs to be achieved but at the same time, maximum bead width is also achieved.

\subsection{Arc Voltage}

Arc voltage does not give significant effect on penetration depth as welding current does but still, arc voltage gives significant effect on the bead width [10, 13]. Also, Shahi and Pandey [14] mentioned that increased arc voltage increases the arc cone, therefore the arc is spread over a larger area of the substrate which leads to less welding penetration; less penetration depth means less dilution of the filler material. However, excessive arc voltage can cause spatter, porosity, and also undercut. Any increment of arc voltage or welding arc will make the heat input of the welding process rises.

\subsection{Travel Speed}

Travel speed gives significant effect on the filler material deposition rate and thermal transmitted to the substrate. Decreasing the travel speed will decrease the thermal transmission to the substrate but increase the filler material deposition rate. However, according to Shahi and Pandey [14], travel speed gives less effect on dilution compared to arc voltage because changing in travel speed will change the geometry of the bead proportionally. Minimum dilution is a target in cladding, therefore lower travel speed is more prefer because by doing so, less penetration is achieved and so, less 
dilution. Higher travel speed is also not preferable because undercutting might occur if travel speed is too high.

\section{CAST IRON}

Cast iron can be defined as an alloy which the main element is iron and the major alloying elements are carbon and silicon. Other alloying elements that would be in the composition of various types of cast iron in the industry today are nickel, copper, chromium, vanadium, molybdenum, boron and more others. It is commonly considered that cast iron is a difficult material to be welded because of the inherent brittleness of the material and the effect of weld thermal cycle on its metallurgical structure [15]. There are five major types of cast iron in the industry today; gray, ductile, white, malleable, and compacted graphite cast iron. The one which is used as the substrate for this research is gray cast iron.

\subsection{Gray Cast Iron}

Gray cast iron, or easily called as gray iron, is the most common form of cast iron. This type of cast iron has moderate strength, excellent damping and machinability, but poor ductility. It contains 2 to $4 \% \mathrm{C}, 1$ to $3 \% \mathrm{Si}$, and up to $1 \% \mathrm{Mn}$, and has a tensile strength up to $275 \mathrm{MPa}$ [16]. It is also reported that gray iron has low hardness value; 25 - 35 HRC $(\sim 260-340 \mathrm{HV})$ [17]. The typical microstructure of gray iron is a matrix of $\alpha$-ferrite or pearlite matrix with graphite flakes spread all over the matrix. Figure 4 shows the optical micrograph of gray cast iron.

\subsection{The Cladding of Gray Cast Iron}

Cladding is a deposition process in which involves producing heat to melting the filler material onto the substrate. The problem lies when gray iron as the substrate is that the material suffers thermal cycle produced by the process. The lack of ductility due to the coarse graphite flakes structure in gray iron makes the material often fails to withstand stresses caused by temperature drop [15]. The inherent brittleness characteristic makes gray iron vulnerable to cracking upon cooling of the process.

Pouranvari [15], in his study on the weldability of gray cast iron using nickel based filler material concluded that the cracking problem can be solved by using nickel based filler material and proper post-weld heat treatment. Using the nickel based filler material alone without post-weld heat treatment just can only solve the problem in fusion zone (FZ) but not in heat affected zone (HAZ) as the thermal cycle of the process allows martensite formation in HAZ that leads to the cracking problem.

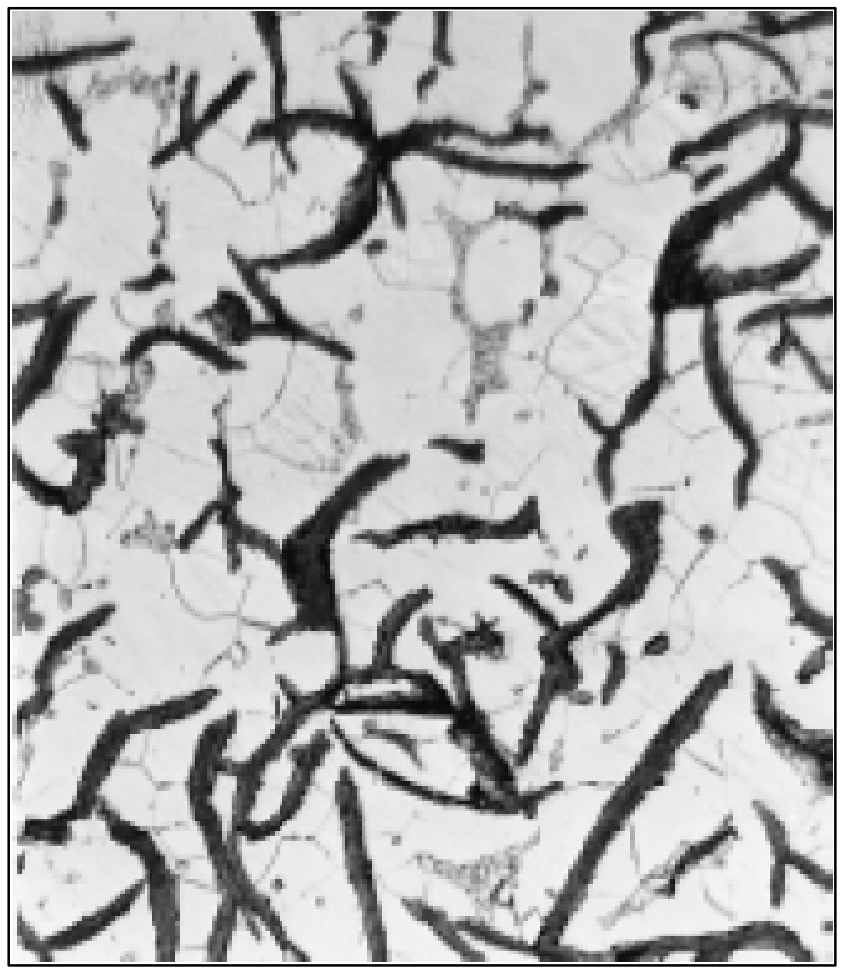

Fig-4: Optical micrograph of gray cast iron with 500x magnification: the dark graphite flakes are embedded in $\alpha$ ferrite matrix [18].

However, even though crack defect always seen as problem and need to be avoided, that depends on the function of the substrate in its real operation. Chatterjee and Pal [6], in their research on wear behavior of cladding on gray iron substrate, where gray iron is used as the material for top bearing plate in coal crushing unit of thermal power plant, mentioned that cracking does not always significantly decrease the service wear life of the component, but occasionally acts as a benefit in decreasing residual stress level.

\section{FILLER MATERIAL}

Filler material for cladding purpose is chosen based on the required final properties of the clad like wear resistance or corrosion resistance for example. Some of the filler materials used for cladding cast iron are copper based alloy, stainless steel, and nickel based alloy [19].

\subsection{Types of Filler Materials for Cladding Cast Iron}

Copper based alloy is used for the purpose of corrosion resistance or building up surfaces of wear. Copper based alloy is also reported can give superior thermal fatigue resistance in laser cladding on gray cast iron [20]. 


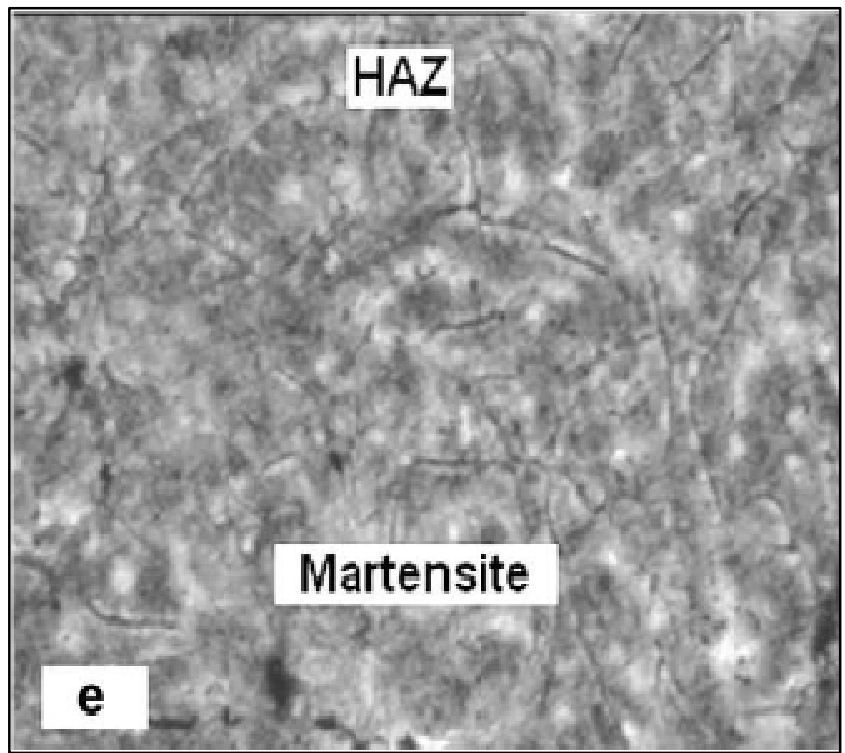

Fig-5: Martensite formation in the heat affected zone of gray iron substrate [15].

Stainless steel filler material is used for increasing the corrosion and oxidation resistance properties. However, when using stainless steel as the filler material in cladding cast iron, the migration of carbon from the substrate into the stainless steel deposit usually cause cracking problem. The absorption of carbon into stainless steel causes the formation of chromium carbide which leads to the cracking problem. This problem is solved by using nickel based alloy for the buffer layer in the clad. Nickel based alloy helps in reducing the carbon migration from the substrate into the stainless steel layer because of the low diffusivity of carbon in nickel based alloy. The disadvantage of using nickel based alloy as the buffer layer is its high cost [6].

Nickel based alloy have the characteristic of outstanding wear and corrosion resistance properties at elevated temperature, either on their own or with the combination of other reinforcement particles [21]. Another advantage in using nickel based alloy as the filler material is the ability precipitates the carbon from the cast iron substrate in the form of graphite, thus preventing the formation of carbide [15]. Among the mechanical parts which used nickel based alloy in their manufacturing are piston rings, rollers in steel making, roller tables, wearing plates and pump shafts in box packing areas [22].

\subsection{Tungsten Carbide Reinforced NiCrBSi Alloy}

Many research in cladding using this alloy for the deposition are done using laser cladding and plasma transferred arc (PTA) technique in which the alloy is supplied in the shape of powder [23, 24, 25, 26, 27]. The addition of tungsten carbide particles in the material significantly increases the wear resistance and the overall hardness of the alloy. Figure 6 shows the alloy with most percentage of tungsten carbide addition has highest wear resistance compare to the ones with less and no tungsten carbide addition whereas Figure 7 shows the comparison in terms of hardness.

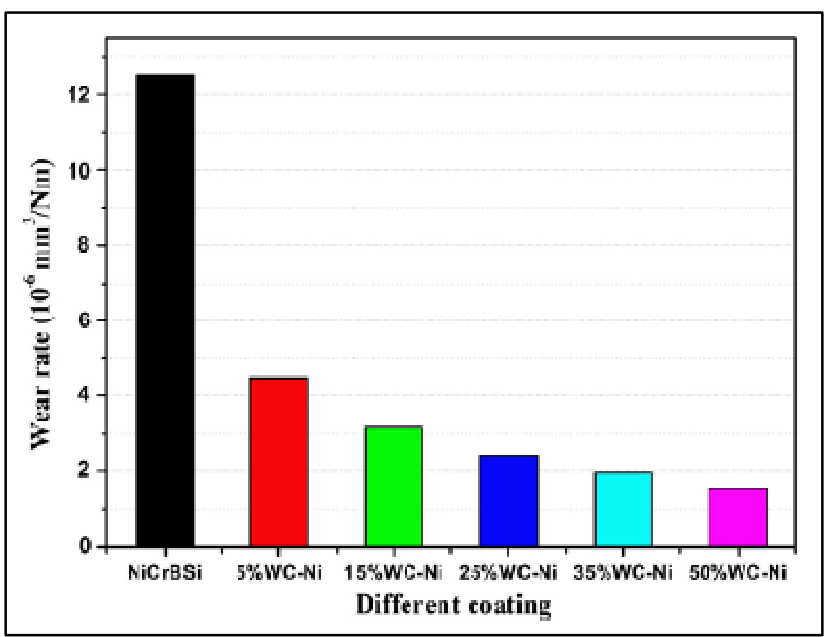

Fig-6: Wear rates of the $\mathrm{NiCrBSi}$ and $\mathrm{NiCrBSi} / \mathrm{WC}-\mathrm{Ni}$ coatings [27].

However, there is not many literature reviews on tungsten carbide reinforced $\mathrm{NiCrBSi}$ alloy consumables deposited using GMAW technique. According to Mendez et al. [28], tungsten carbide (WC) reinforced nickel based alloy consumables usually available with $\mathrm{NiBSi}$ or NiCrBSi matrix alloy with the matrix microstructure is usually contained of soft primary nickel dendrites with relatively low hardness of about $350 \mathrm{HV}$ whereas the inter-dendritic regions consist of hard carbides, borides, and silicides with hardness of about 500 to $800 \mathrm{HV}$. Figure 8 shows the backscattered SEM micrograph of the alloy microstructure obtained using GMAW and hot-wire GMAW.

The tungsten carbide (WC and $\mathrm{W} 2 \mathrm{C}$ phases) reinforced $\mathrm{NiCrBSi}$ filler alloy was also reported to have even higher hardness; the NiCrBSi matrix having the hardness of 560 to $620 \mathrm{HV}$ and the carbides having the hardness of $2340 \mathrm{HV}$ [29]. In this research, the tungsten carbide reinforced in NiCrBSi matrix alloy consumable will be used for cladding using GMAW technique.

\section{CONCLUSIONS}

Gray cast iron is difficult to welded mainly because the natural characteristic of cast iron which is inherently brittle and has tendency to cracking when subjected to the temperature drop cause by the arc welding process. The weld cladding by using gas metal arc welding technique and method would be accomplished effectively without cracking by choosing nickel based alloy as the filler material. 


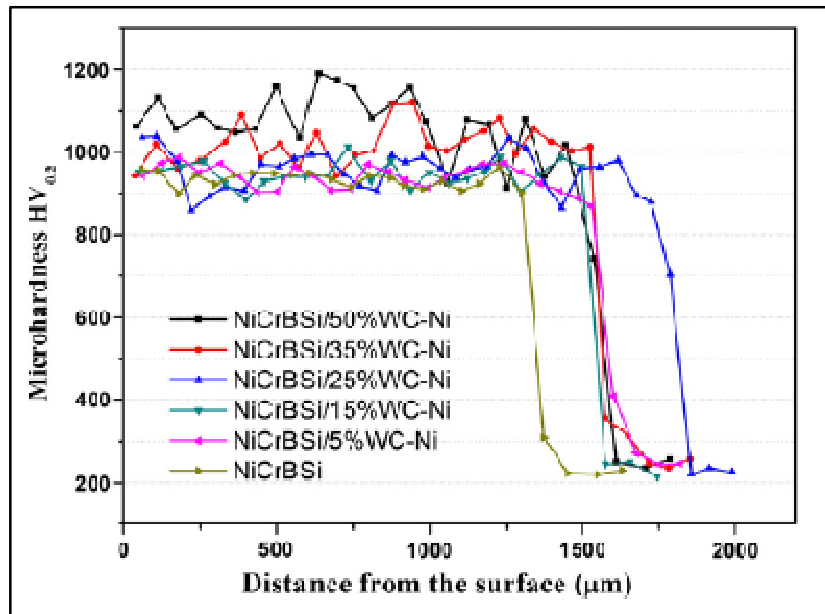

Fig-7: Micro hardness profiles of the NiCrBSi and $\mathrm{NiCrBSi} / \mathrm{WC}-\mathrm{Ni}$ coatings [27].

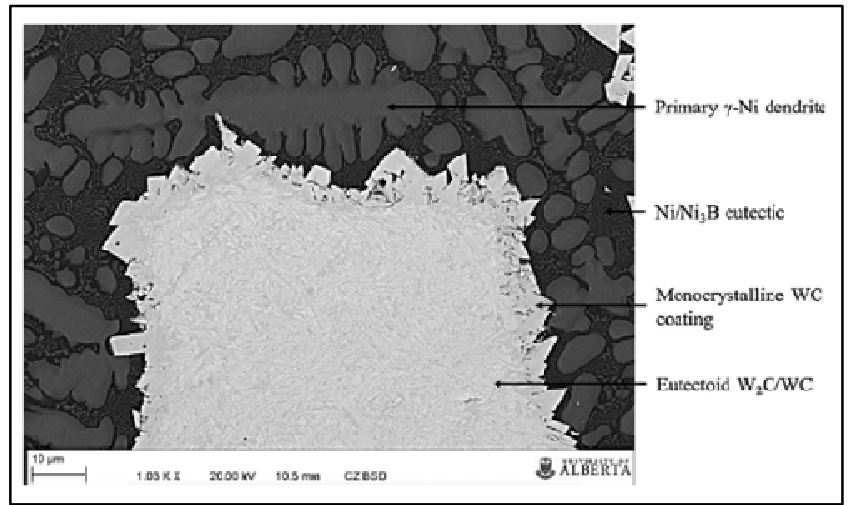

Fig-8: Backscattered SEM micrographs of typical Ni-WC alloys microstructure obtained using GMAW and hot-wire GMAW [28].

The nickel based alloy material can prevent the migration of carbon from the cast iron substrate into the fusion zone thus preventing the carbide phase to form in the fusion zone. Moreover, nickel can precipitate the carbon in the form of graphite therefore the martensite formation can be prevented.

The reinforcement of tungsten carbide into the nickel based alloy matrix provides high wear resistant and hardness properties. The tungsten carbide reinforced alloy filler material is available in the form of powder to be used in laser cladding and also in the form of wire to be used with gas metal arc welding equipment. While laser cladding technique is the more popular choice to perform the cladding process, gas metal arc is more economic yet flexible in its operation. Future work should focus more detail on the technique of the cladding operation using GMAW equipment in optimizing the process parameters to find the right combination of the parameters with optimum values to maximize the required properties of the clad beside performing the cladding operation experiment.

\section{REFERENCES}

[1]. V.E. Buchanan, P.H. Shipway, D.G. McCartney, Microstructure and abrasive wear behaviour of shielded arc welding hardfacings used in the sugarcane industry, Wear 263 (2007) 99-110.

[2]. N. Venkateswara Rao, G. Madhusudhan Reddy, S. Nagarjuna, Weld overlay cladding of high strength low alloy steel with austenitic stainless steel - Structure and properties, Materials and Design 32 (2011) 2496-2506.

[3]. Andreas Lundbäck, Lars-Erik Lindgren, Modelling of metal deposition, Finite Elements in Analysis and Design 47 (2011) 1169-1177.

[4]. N. I. S. Hussein, N. F. Asri, M. H. Shahroom and S. R. Shamsuri, Microstructure and Microhardness of Stainless Steel Single Bead Clad Deposited Using Gas Metal Arc Heat Source, iDECON 2012 - International Conference on Design and Concurrent Engineering 2012.

[5]. T. Branza, F. Deschaux-Beaume, G. Sierra, P. Lours, Study and prevention of cracking during weld-repair of heat-resistant cast steels, Journal of Materials processing Technology 209 (2009) 536-547.

[6]. S. Chatterjee, T.K. Pal, Wear behaviour of hardfacing deposits on cast iron, Wear 255 (2003) 417-425.

[7]. D. Clark, M. R. Bache, M. T. Whittaker, Shaped metal deposition of a nickel alloy for aero engine applications, Journal of Materials Processing Technology 203 (2008) 439-448.

[8]. F. Schneebeli, O. Braun, B. Tanner, R. Dekumbis, Method of production of workpieces by welding equipment, U. S. Patent, Editor 1993, Sulzer Brothers Limited, Winterthur, Switzerland.

[9]. YuMing Zhang, Yiwei Chen, Pengjiu Li, Alan T. Male, Weld deposition-based rapid prototyping: a preliminary study, Journal of Materials Processing Technology 135 (2003) 347-357.

[10]. Erdal Karadeniz, Ugur Ozsarac, Ceyhan Yildiz, The effect of process parameters on penetration in gas metal arc welding processes, Materials and Design 28 (2007) 649-656.

[11]. Izzatul Aini Ibrahim, Syarul Asraf Mohamat, Amalina Amir, Abdul Ghalib, The Effect of Gas Metal Arc Welding (GMAW) processes on different welding parameters, Procedia Engineering 41 ( 2012 ) 15021506.

[12]. P.K. Palani, N. Murugan, Optimization of weld bead geometry for stainless steel claddings deposited by FCAW, Journal of Materials Processing Technology 190 (2007) 291-299.

[13]. R. S. parmar, Welding processes and technology, $2^{\text {nd }}$ ed., New delhi: Khanna Pub., 2008. 
[14]. A.S. Shahia, Sunil Pandey, Modelling of the effects of welding conditions on dilution of stainless steel claddings produced by gas metal arc welding procedures, Journal of Materials Processing Technology 196 (2008) 339-344.

[15]. M. Pouranvari, On the weldability of grey cast iron using nickel based filler metal, Materials and Design 31 (2010) 3253-3258.

[16]. R. A. Bushery, Welding of Cast Irons, In: ASM Handbook - Welding, Brazing, and Soldering, Ohio, U. S. A., ASM International, 2000.

[17]. Sandvick Coromant, Productivity in Die \& Mould Making, 2010 [Online]. Available at: http://www2.coromant.sandvik.com/coromant/pdf/dm cat/003_031.pdf [Accessed on 15 Oct 2012].

[18]. W. D. Callister, Fundamentals of materials science and engineering, $3^{\text {rd }}$ ed., John Wiley, 2008.

[19]. J. R. Davis, Cast Irons, ASM Specialty Handbook, ASM International, 1996.

[20]. Xin Tong, Fu-hai Li, Min Liu, Ming-jiang Dai, Hong Zhou, Thermal fatigue resistance of non-smooth cast iron treated by laser cladding wih different self-fluxing alloys, Optics \& Laser Technology 42 (2010) 11541161.

[21]. E. Fernández, M. Cadenas, R. González, C. Navas, R. Fernández, J. de Damborenea, Wear behaviour of laser clad NiCrBSi coating, Wear 259 (2005) 870-875.

[22]. J. Rodríguez, A. Martín, R. Fernández, J. E. Fernández, An experimental study of the wear performance of NiCrBSi thermal spray coatings, Wear 255 (2003) 950955.

[23]. Shengfeng Zhoua, Xiaoqin Dai, Laser induction hybrid rapid cladding of WC particles reinforced $\mathrm{NiCrBSi}$ composite coatings, Applied Surface Science 256 (2010) 4708-4714.

[24]. T. Liyanage, G. Fisher, A.P. Gerlich, Influence of alloy chemistry on microstructure and properties in $\mathrm{NiCrBSi}$ overlay coatings deposited by plasma transferred arc welding (PTAW), Surface \& Coatings Technology 205 (2010) 759-765.

[25]. T. Liyanage, G. Fisherb, A.P. Gerlich, Microstructures and abrasive wear performance of PTAW deposited $\mathrm{Ni}-\mathrm{WC}$ overlays using different Ni-alloy chemistries, Wear 274- 275 (2012) 345- 354.

[26]. Chun Guo, Jiansong Zhou, Jianmin Chen, Jierong Zhao, Youjun $\mathrm{Yu}$, Huidi Zhou, High temperature wear resistance of laser cladding $\mathrm{NiCrBSi}$ and $\mathrm{NiCrBSi} / \mathrm{WC}$ Ni composite coatings, Wear 270 (2011) 492-498.

[27]. Chun Guo, Jianmin Chen, Jiansong Zhou, Jierong Zhao, Lingqian Wang, Youjun Yu, Huidi Zhou, Effects of $\mathrm{WC}-\mathrm{Ni}$ content on microstructure and wear resistance of laser cladding $\mathrm{Ni}$-based alloys coating, Surface \& Coatings Technology 206 (2012) 20642071.

[28]. Patricio F. Mendez, Nairn Barnes, Kurtis Bell, Steven D. Borle, Satya S. Gajapathi, Stuart D. Guest, Hossein Izadi, Ata Kamyabi Gol, Gentry Wood, Welding processes for wear resistant overlays, Journal of Manufacturing Processes, In Press (2013).

[29]. Leonard Choi, Tonya Wolfe, Matthew Yarmuch, Adrian Gerlich, Effect of Welding Parameters on Tungsten Carbide - Metal Matrix Composites Produced by GMAW, Manuscript accepted in the Canadian Welding Association Conference, Sept. 28, 2010.

\section{BIOGRAPHIES}

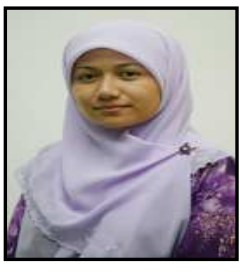

processes.

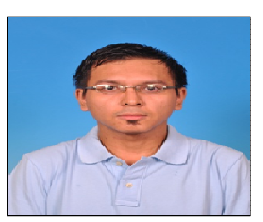

cladding process.

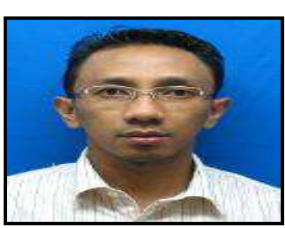

Mohamad Nizam b. Ayof is a senior lecturer in the Department of Manufacturing Process in Faculty of Manufacturing Engineering in Universiti Teknikal Malaysia Melaka (UTeM), Malacca, Malaysia. His research areas are physics and laser cutting. 